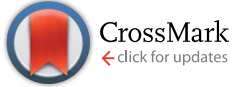

Cite this: RSC Adv., 2016, 6, 80398

Received 27th June 2016

Accepted 24th July 2016

DOI: $10.1039 / c 6 r a 16606 g$

www.rsc.org/advances

\section{The evolution of hierarchical porosity in self- templated nitrogen-doped carbons and its effect on oxygen reduction electrocatalysis $\uparrow$}

\author{
David Eisenberg, ${ }^{\star a}$ Pepijn Prinsen, ${ }^{a}$ Norbert J. Geels, ${ }^{a}$ Wowa Stroek, ${ }^{a}$ Ning Yan, ${ }^{a}$ \\ Bin Hua, ${ }^{b}$ Jing-Li Luo ${ }^{b}$ and Gadi Rothenberg*a
}

Pyrolitic self-templating synthesis is an effective method for creating hierarchically porous $\mathrm{N}$-doped carbons. We study the evolution of microstructure in self-templated carbons derived from magnesium nitrilotriacetate, in the $600-1000{ }^{\circ} \mathrm{C}$ temperature range. The materials are characterised using $\mathrm{N}_{2}$ adsorption, $\mathrm{Hg}$ intrusion, X-ray diffraction, X-ray photoelectron spectroscopy, Raman spectroscopy, elemental analysis, scanning electron microscopy and transmission electron microscopy. The carbons display high specific surface areas (up to $1830 \mathrm{~m}^{2} \mathrm{~g}^{-1}$ ), and high pore volumes (up to $3.1 \mathrm{~mL} \mathrm{~g}^{-1}$ ). Interestingly, each porosity type - micro, meso, and macro - evolves along its own route. Micropore growth is most significant between 600 and $700{ }^{\circ} \mathrm{C}$, yet it slows down and stops around $800{ }^{\circ} \mathrm{C}$; this indicates that micropores form by removal of tarry matter from the interstices between graphitic sheets, rather than by physical/chemical etching of these sheets. Mesopores, templated by spontaneously forming $\mathrm{MgO}$ nanoparticles, become dominant at $800{ }^{\circ} \mathrm{C}$; further agglomeration of these particles leads to macropore templating at $900{ }^{\circ} \mathrm{C}$. The porosity evolution is explained by the growth of $\mathrm{MgO}$ particles, as monitored by XRD broadening. Furthermore, the degree of disorder decreases with the pyrolysis temperature, most significantly between 700 and $800{ }^{\circ} \mathrm{C}$, with the Raman $I_{\mathrm{D}} / \mathrm{I}_{\mathrm{G}}$ ratio dropping from 1.36 to 1.17. Correspondingly, the in-plane length of graphitic crystallites increases along the series, from 14 to $17 \mathrm{~nm}$. Although the nitrogen content decreases with pyrolysis temperature, from 6.9 to 4.1 at\%, the ratio between graphitic and pyridinic nitrogens remains constant. We then measure the performance of these carbons as electrocatalysts in the oxygen reduction reaction (ORR) at $\mathrm{pH} 13$ using rotating disk electrode voltammetry and electrochemical impedance spectroscopy. Remarkably, the ORR activity trend is independent of nitrogen concentration or degree of disorder. Instead, it is governed by the microstructural parameters, most importantly surface area and microporosity.

\section{Introduction}

Activated carbon has been used as a dye and adsorbent for millennia, ${ }^{1-4}$ and in catalysis for decades. ${ }^{5,6}$ Lately, carbon has been hailed as a promising electrode material for electrochemical charge storage ${ }^{7}$ in batteries, ${ }^{7-9}$ supercapacitors, ${ }^{\mathbf{1 0 - 1 3}}$ and fuel cells. ${ }^{\mathbf{1 4 - 1 7}}$ Specifically, carbons doped with heteroatoms such as nitrogen are a leading alternative to platinum as electrocatalysts in the oxygen reduction reaction (ORR) in alkaline solutions. ${ }^{18-24}$

\footnotetext{
${ }^{a}$ Van 't Hoff Institute for Molecular Sciences, University of Amsterdam, Science Park 904, 1098 XH, Amsterdam, The Netherlands. E-mail: d.eisenberg@uva.nl; g. rothenberg@uva.nl; Tel: +31-20-5256963

${ }^{b}$ Department of Chemical and Materials Engineering, University of Alberta, Edmonton, Alberta, T6G 2V4, Canada
}

$\uparrow$ Electronic supplementary information (ESI) available. See DOI: 10.1039/c6ra16606g
Both the elemental composition and the microstructure of carbon determine its catalytic performance. ${ }^{15-31}$ Carbon comprises matter $\left(\mathrm{sp}^{3} / \mathrm{sp}^{2}\right.$ carbon ratio, doping, crystallinity) and voids (pore sizes, shapes and distribution). Micropores ( $d$ $<2 \mathrm{~nm}$ ) provide most of the surface area of the material. This means that most catalytic active sites are located in micropores. ${ }^{3}$ Mesopores $(d=2-50 \mathrm{~nm})$ contribute more to the internal volume of the carbon, serving as immediate reservoirs for reagents and enabling the transfer of reagents/ products to/from the micropores. ${ }^{32}$ In some cases, the mesopores are small enough to affect reaction pathways by confinement effects. ${ }^{33}$ Finally, macropore channels $(d>50$ $\mathrm{nm}$ ) are the highways for mass transfer through the carbon, contributing most to its internal volume. ${ }^{34}$ The different pore levels must intersect, to enable the splitting of reagent/ product flow; only then can porosity be termed 'hierarchical' (Fig. 1). ${ }^{21-23,35-37}$

Yet carbon structure is easier described than designed. Carbon synthesis protocols come in two very different types: 


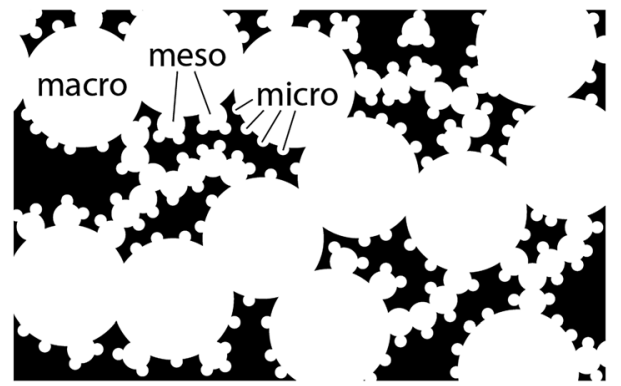

Fig. 1 Scheme of hierarchical porosity (type II), ${ }^{37}$ showing intersecting pore types.

empirical and rational. In the former, abundant carbonaceous precursors (biomass-based or petro-based) are pyrolyzed in hope for serendipity. ${ }^{38-43}$ The resulting carbons are easily made and cheap, but controlling their porosity and composition is difficult. In the latter, chemical precursors are transformed with various external templating methods. This allows a high degree of control over the material properties, but preparation is more complex and costly. External templating methods include hard templating ${ }^{44-47}$ (e.g. on silica, which is then etched away by HF) and soft templating (based on organic self-assembly). ${ }^{36,48,49}$ Other methods for controlling carbon structure include pyrolyzing preformed aerogels ${ }^{50,51}$ and the etching of pores by chemical and physical means. ${ }^{3}$

Self-templating is a powerful route to hierarchical porous carbons. ${ }^{52-59}$ In this approach, simple metal-organic salts such as magnesium citrate are used as both carbon precursor and templating agent. During pyrolysis, nano-sized metal oxide particles (e.g. $\mathrm{MgO}$ ) form within the carbon matrix. Washing out these particles leaves behind mesopores (in case of single nanoparticles) and macropores (for nanoparticle agglomerates). Recently, we reported the discovery of a family of self-templating nitrogen-doped carbons, based on the pyrolysis of various magnesium nitrilotriacetates (MgNTA). ${ }^{23,30}$ These carbons exhibit an interpenetrating network of micropores, mesopores and macropores, lined with graphitic shells. However, despite having advantages such as hierarchical porosity, graphitic network and high doping, the challenge of 'designability' remains open. To address it, we must first understand the mechanism of pyrolytic self-templating.

We now report a detailed study into the evolution of microstructure and composition in MgNTA-derived carbons, in the $600-1000{ }^{\circ} \mathrm{C}$ temperature range. Using a broad array of experimental techniques, we follow the surface area, internal volume, micro-/meso-/macro-pore distribution, size of templating $\mathrm{MgO}$ nanoparticles, degree of graphitization, and nitrogen content and distribution. The result is a step-by-step description of how micropores are formed, and how mesopore-templating nanoparticles of $\mathrm{MgO}$ grow and agglomerate. Finally, we test how the evolving microstructure and composition affect the carbons' ORR activity at $\mathrm{pH} 13$, a reaction of rising importance due to the rise of alkaline exchange membranes for fuel cells. ${ }^{20}$

\section{Experimental}

\subsection{Procedure for synthesis of hierarchical porous carbons}

This is a modification of a previously published procedure. ${ }^{23}$ Briefly, magnesium nitrilotriacetate $\left(\mathrm{MgNH}\left(\mathrm{CH}_{2} \mathrm{COO}\right)_{3}\left(\mathrm{H}_{2} \mathrm{O}\right)_{3}\right)$ was precipitated from a 1:1 solution of basic magnesium carbonate (Strem) and nitrilotriacetic acid (Aldrich) at $85{ }^{\circ} \mathrm{C}$. After drying and grinding, the salt was pyrolyzed at a range of temperatures $\left(600-1000^{\circ} \mathrm{C}\right)$ in $\mathrm{Ar}$ atmosphere for $1 \mathrm{~h}$ (heating rate $10^{\circ} \mathrm{C} \mathrm{min}^{-1}$ ). The resulting $\mathrm{MgO} @ \mathrm{~N}: \mathrm{C}$ composite was washed in citric acid $(0.5 \mathrm{M})$ overnight, dried, and annealed in argon $\left(1000{ }^{\circ} \mathrm{C} / 1 \mathrm{~h}\right.$, heating rate of $\left.5{ }^{\circ} \mathrm{C} \mathrm{min}^{-1}\right)$.

\subsection{Characterization of materials}

Thermogravimetric analysis (TGA) was done on a Netzch Jupiter® STA $449 \mathrm{~F} 3$ instrument, under argon $\left(20 \mathrm{~mL} \mathrm{~min}^{-1}\right)$ between 30 and $800{ }^{\circ} \mathrm{C}$. Transmission electron microscopy (TEM) was done on a Tecnai Osiris microscope at an accelerating voltage of $200 \mathrm{kV}$. Scanning electron microscopy (SEM) was done on a Zeiss EVO50 microscope operated at $15 \mathrm{kV} . \mathrm{N}_{2}$ adsorption-desorption isotherms were measured on a Thermo Scientific Surfer instrument at $77 \mathrm{~K}$, using vacuum dried samples $\left(200^{\circ} \mathrm{C} / 3 \mathrm{~h}\right)$. Isotherms were analyzed by the ThermoFischer Advanced Data Processing 6.0 software. The isotherms were analyzed using the two-parameter Brunauer-EmmettTeller (BET2) model for specific surface area, the DubininRadushkevitch model for micropore volume, the HorvathKawazoe method for micropore size distribution, and non-local density functional theory (NLDFT) isotherm fitting for mesomacropore size distribution. In the latter, the model used was $\mathrm{N}_{2}$ /graphite at $77 \mathrm{~K}$, with slit-shaped pores (giving a better fit than cylindrical pores). Helium density was measured on a Micromeritics Multivolume Pycnometer 1305. Mercury intrusion was carried out on a Pascal 440 Porosimeter (CE Instruments) up to $400 \mathrm{MPa}$, on the same pre-treated samples. X-Ray diffraction (XRD) patterns were obtained with a MiniFlex II diffractometer using Ni-filtered $\mathrm{Cu}-\mathrm{K}_{\alpha}$ radiation, at $30 \mathrm{kV}$ and 15 $\mathrm{mA}$. Approximate sizes of the coherently scattering domains $(D)$ were calculated using the Scherrer equation:

$$
D=\frac{0.94 \lambda_{\mathrm{X}}}{\beta \cos \theta}
$$

where $\lambda_{\mathrm{X}}$ is the $\mathrm{X}$-ray wavelength $(1.54056 \AA$ for $\mathrm{Cu}-\mathrm{K} \alpha), \beta$ is the line broadening (in rad), and $\theta$ is the Bragg angle. This equation only accounts for size-dependent broadening, so it gives a lower limit for actual particle sizes..$^{60,61}$ No calibration was done to account for instrument broadening, so the calculated $D$ values are limited to studying trends within the series.

Raman spectroscopy was performed on a Thermo Nicolet Almega XR Dispersive Raman microscope, with a $\times 50$ lens and 10 exposures of $5 \mathrm{~s}$. The laser wavelength is $532 \mathrm{~nm}(24 \mathrm{~mW})$. First-order Raman spectra were fit iteratively with four Lorentzian components, based on literature assignments. ${ }^{62-66}$ The in-plane ( $a$ direction) lengths of graphitic crystallites $\left(L_{\mathrm{a}}\right)$ were calculated from the intensity ratios of fitted D and G bands, according to the relation determined by Cançado et al. ${ }^{67}$ 


$$
L_{\mathrm{a}}=\left(2.4 \times 10^{-10}\right) \lambda_{\mathrm{l}}{ }^{4}\left(\frac{I_{\mathrm{D}}}{I_{\mathrm{G}}}\right)^{-1}
$$

where $\lambda_{1}$ is the laser wavelength $(532 \mathrm{~nm})$.

X-Ray photoelectron spectroscopy (XPS) measurements were carried out using a PHI VersaProbe II scanning XPS microprobe (Physical Instruments AG, Germany). Analysis was performed using a monochromatic $\mathrm{Al} \mathrm{K \alpha} \mathrm{X}$-ray source of $24.8 \mathrm{~W}$ power with a beam size of $100 \mu \mathrm{m}$. The spherical capacitor analyzer was set at a $45^{\circ}$ take-off angle with respect to the sample surface. The pass energy was $46.95 \mathrm{eV}$ yielding a full width at half maximum of $0.91 \mathrm{eV}$ for the $\mathrm{Ag} 3 \mathrm{~d}_{5 / 2}$ peak. Peaks were calibrated using the C 1s position. Curve fitting was done using XPSPeak 4.1.

\subsection{Procedure for electrochemical measurements}

Inks of the carbon powders $(0.80 \mathrm{~mL}$ DI water, $0.20 \mathrm{~mL}$ ethanol, $10 \mu \mathrm{L}$ Nafion ${ }^{\circledR} 5 \mathrm{wt} \%$ dispersion (Alfa Aesar), $1.0 \mathrm{mg}$ carbon powder) were sonicated and dropcast $(3 \times 10 \mu \mathrm{L})$ on a polished $\phi=5 \mathrm{~mm}\left(A=0.196 \mathrm{~cm}^{2}\right)$ glassy carbon electrode (Gamry), and dried at $50{ }^{\circ} \mathrm{C}$. Total catalyst loading was $30 \mu \mathrm{g}$, or $153 \mu \mathrm{g} \mathrm{cm}{ }^{-2}$. Electrochemical experiments were performed in $0.1 \mathrm{M} \mathrm{KOH}$ at $25.0 \pm 0.1{ }^{\circ} \mathrm{C}$, using a Gamry Reference 600 potentiostat and a Gamry RDE710 Rotating Electrode setup. Saturated calomel electrode (SCE) separated by a $10 \mathrm{~cm}$ bridge was used as a reference electrode, and a graphite rod as a counter electrode. Potentials were reported $v s$. reversible hydrogen electrode (RHE) by adding 1.011 for $\mathrm{pH}$ 13. $\mathrm{N}_{2}$ or $\mathrm{O}_{2}$ (both $99.999 \%$ ) were bubbled for $>60 \mathrm{~min}$ to saturate the solution, and were flowed above the solution during the experiments. Voltammograms were collected from 1.01 to $0.31 \mathrm{~V} v s$. RHE with a scan rate of 10 $\mathrm{mV} \mathrm{s}^{-1}$. RDE voltammograms were collected at rotating speeds of 2400, 2000, 1600, 1200, 900, 600 and 400 rpm. Reported current densities represent faradaic currents, after subtracting the capacitive charging background current. The solution resistance (typically $44-48 \mathrm{ohm}$ ) was measured prior to each measurement set. A positive feedback automatic iR correction of $90 \%$ was used. Before measurements, surface adsorbed oxygen was reduced and the wetting was improved by cycling the electrode between 0 and $-0.7 \mathrm{~V} v s$. SCE for 20 cycles at 50 $\mathrm{mV} \mathrm{s}{ }^{-1}$. Electrochemical impedance spectroscopy (EIS) was measured potentiostatically at $\pm 5 \mathrm{mV}$ around the half-wave potential for ORR, while bubbling oxygen and rotating at 1600 rpm. The electrochemical impedance spectroscopy frequency range was $0.2-10^{6} \mathrm{~Hz}$. The number of moles of electrons transferred per mol $\mathrm{O}_{2}(n)$ was estimated by the Koutecký-Levich equation

$$
\frac{1}{J}=\frac{1}{B \omega^{1 / 2}}+\frac{1}{J_{\mathrm{K}}}
$$

where $J$ is the measured current density $\left(\mathrm{mA} \mathrm{cm}{ }^{-2}\right), J_{\mathrm{K}}$ the kinetic (exchange) current density $\left(\mathrm{mA} \mathrm{cm} \mathrm{cm}^{-2}\right)$, and $\omega$ is the electrode rotation rate (rpm). The term $B$ is given by

$$
B=0.2 n F C_{\mathrm{O}} D_{\mathrm{O}}^{2 / 3} \nu^{-1 / 6}
$$

where $F$ is Faraday's constant $\left(96485 \mathrm{C} \mathrm{mol}^{-1}\right), C_{\mathrm{O}}$ is the concentration of dissolved $\mathrm{O}_{2}\left(1.2 \mathrm{mM}\right.$ at $25{ }^{\circ} \mathrm{C}$ in $\left.0.1 \mathrm{M} \mathrm{KOH}\right)$,
$D_{\mathrm{O}}$ is the diffusion coefficient of $\mathrm{O}_{2}\left(1.9 \times 10^{-5} \mathrm{~cm}^{2} \mathrm{~s}^{-1}\right.$ at $25{ }^{\circ} \mathrm{C}$ in $0.1 \mathrm{M} \mathrm{KOH}$ ), and $\nu$ is the kinematic viscosity of the $0.1 \mathrm{M} \mathrm{KOH}$ electrolyte at $25{ }^{\circ} \mathrm{C}\left(0.01 \mathrm{~m}^{2} \mathrm{~s}^{-1}\right)$. By plotting $1 / \mathrm{J}$ versus $1 / \omega^{1 / 2}$ at different potentials and fitting linear equations to the data, the number of electrons could be calculated from the $1 / B$ slope.

\section{Results and discussion}

\subsection{Microstructure of the carbons}

$\mathrm{N}$-Doped carbons were prepared by pyrolyzing magnesium nitrilotriacetate at five different temperatures between $600{ }^{\circ} \mathrm{C}$ and $1000{ }^{\circ} \mathrm{C}$ (see Experimental section 2.1 for full procedure). Sample names denote the pyrolysis temperature in ${ }^{\circ} \mathrm{C}$ (C600, C700, C800, C900 and C1000). All of the MgO-free carbons were then annealed at the same temperature $\left(1000{ }^{\circ} \mathrm{C}\right)$, removing any surface functionalities introduced during the acid wash step. ${ }^{23,53,54}$ Carbonization of MgNTA is complete at $540{ }^{\circ} \mathrm{C}$, according to the thermogravimetric analysis in argon (Fig. $\mathrm{S} 1 \dagger$ ). The reactions occurring during carbonization were described by Budkuley and Naik. ${ }^{68}$ Here, we will focus on the subsequent microstructural changes.

The surface area and porosity of the carbons were studied using $\mathrm{N}_{2}$ adsorption. Fig. 2a shows the $\mathrm{N}_{2}$ adsorption-desorption isotherms at $77 \mathrm{~K}$ for carbons $\mathrm{C} 600$ to $\mathrm{C} 1000$, as a function of equilibrium relative pressure $\left(P / P^{0}\right.$, where $P^{0}$ is the saturation pressure of $\mathrm{N}_{2}$ at $\left.77 \mathrm{~K}\right) .{ }^{69}$ The initial sharp rise at $P / P^{0}<0.01$ corresponds to micropore filling, a primary physisorption process distinct from surface adsorption. The magnitude of the rise in carbons $\mathrm{C} 700-\mathrm{C} 1000$ reflects abundant micropores. The consequent slope $\left(P / P^{0}>0.2\right)$ corresponds to the filling of mesopores with monolayers and multilayers of $\mathrm{N}_{2}$. The ultimate rise $\left(P / P^{0}>0.8\right)$ and subsequent desorption hysteresis are characteristic for capillary condensation in the finite-volume of the mesopores. While C600 exhibits a type III isotherm (typical for nonporous solids), C700-C1000 show typical type IVa isotherms, characteristic for micro-mesoporous materials. ${ }^{69}$ The hysteresis loops in the latter are type $\mathrm{H} 4{ }^{69}$ Such hysteresis may arise by different mechanisms, such as adsorption metastability (delayed condensation), pore blocking at narrow pore necks, and/or cavitation-induced evaporation. ${ }^{69}$

The carbons exhibit specific surface areas (SSAs) as high as $1830 \mathrm{~m}^{2} \mathrm{~g}^{-1}$ (C900, Fig. 2b and Table 1) and total pore volumes as reaching $3.1 \mathrm{~mL} \mathrm{~g}^{-1}\left(\mathrm{C} 900\right.$, at $\left.P / P^{0}=0.99\right)$. While high SSAs are often observed in activated carbons, the high pore volumes reveal the predominance of mesopores and macropores. By quantifying the micropore volumes with the Dubinin-Radushkevitch model, we could separate the contributions of different pore types to the total volume (Fig. $2 \mathrm{c}$ and Table 1). The relative volume of mesopores and macropores is high - it rises from $65 \%$ in $\mathrm{C} 600$ to a stable $76-80 \%$ in C800-C1000. Moreover, while all pore types increase in volume as a function of the pyrolysis temperature, the micropore volume increases by a factor of 4, while the combined mesopore and macropore volume by as much as a factor of 9 (C600 vs. C900). When the pyrolysis temperature is further raised from $900{ }^{\circ} \mathrm{C}$ to $1000{ }^{\circ} \mathrm{C}$, the surface area starts shrinking, probably due to pores collapsing. ${ }^{70,71}$ 

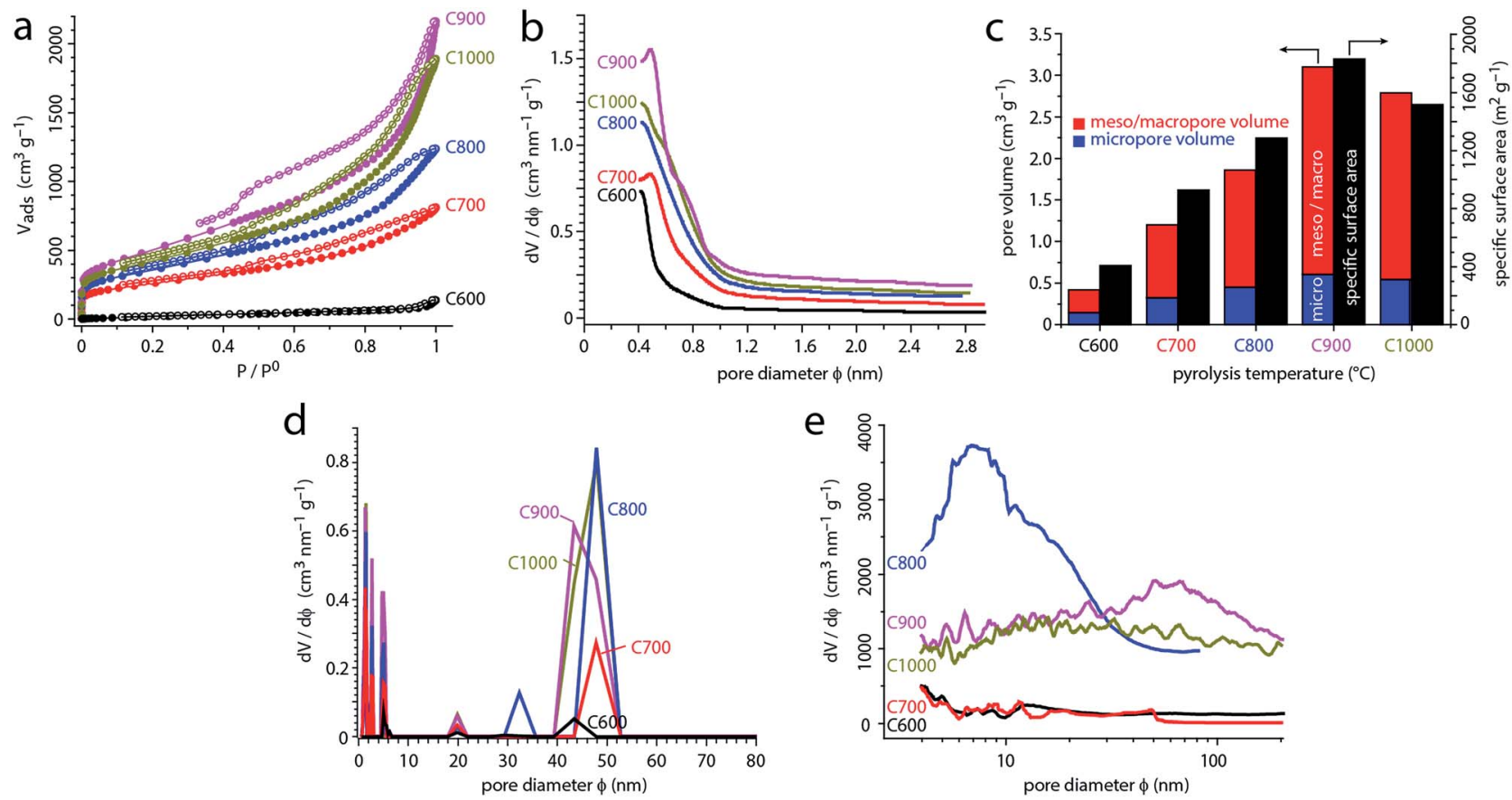

Fig. 2 Porosimetry on carbons pyrolyzed at $600-1000^{\circ} \mathrm{C}$. (a) $\mathrm{N}_{2}$ adsorption-desorption isotherms (filled and empty circles, respectively) at $77 \mathrm{~K}$. (b) Micropore size distribution, calculated from the $\mathrm{N}_{2}$ adsorption data by the Horvath-Kawazoe method. (c) Left axis: volumes of micropores (blue, calculated by the Dubinin-Radushkevich method from the $\mathrm{N}_{2}$ adsorption data) and mesopores + macropores (red, obtained by subtracting the micropore volumes from the total nitrogen adsorbed at 0.99 relative pressure). Right axis (black): specific surface areas, calculated by the BET2 method. (d) Pore size distributions calculated by NLDFT from the $\mathrm{N}_{2}$ adsorption-desorption isotherms. (e) Pore size distributions obtained by $\mathrm{Hg}$ intrusion, focusing on the pore diameter range which corresponds to intraparticulate pores.

To follow and quantify the evolution of microporosity, we analyzed the $\mathrm{N}_{2}$ monolayer formation using the HorvathKawazoe model (Fig. 2b). ${ }^{72}$ In all the carbons, micropores are smaller than $1 \mathrm{~nm}$. Micropores grow as the pyrolysis temperature is increased, and the most significant increase in micropore sizes occurs between 600 and $700{ }^{\circ} \mathrm{C}$. Further growth slows down and finally stops: there is barely any change in the microporosity from $800{ }^{\circ} \mathrm{C}$ to $1000{ }^{\circ} \mathrm{C}$. Yet how do these micropores form? According to the TGA, the carbon loses 5.7\% of its weight ( 0.84 percentage points in Fig. S1 $\dagger$ ) between $550{ }^{\circ} \mathrm{C}$ and $800{ }^{\circ} \mathrm{C}$. This, together with the growth deceleration, suggests that micropores form between $600{ }^{\circ} \mathrm{C}$ and $800{ }^{\circ} \mathrm{C}$ due to the elimination of tar from the interstices between the carbon sheets. $^{3}$ When this "tar supply" runs out $\left(>800{ }^{\circ} \mathrm{C}\right)$, the pore growth decelerates and stops. This is the most plausible mechanism in the absence of external activation agents. ${ }^{3}$

The $\mathrm{N}_{2}$ adsorption data can be further analyzed using NLDFT isotherm fitting, giving information about mesopores and macropores (Fig. 2d and S2 $\dagger$ ). According to Fig. 2d, all carbons contain small $(\sim 5 \mathrm{~nm})$, medium $(\sim 20 \mathrm{~nm})$ and large $(\sim 40-50$ $\mathrm{nm})$ mesopores. All pore types become more abundant at higher pyrolysis temperatures. The NLDFT-derived pore size distributions are more qualitative, as they depend on a range of mathematical and physical assumptions for the fitting process.,72 However, this method does shed some light on pore growth, especially at the transition between C800 and C900-C1000. The former shows two separate pore sizes at $\sim 33$ and $\sim 48 \mathrm{~nm}$, while the latter show a broader pore cluster at $\sim 40-50 \mathrm{~nm}$. This

Table 1 Microstructural, compositional, and electrocatalytic properties of the MgNTA-derived carbons ${ }^{a}$

\begin{tabular}{|c|c|c|c|c|c|c|c|c|c|c|c|c|c|c|c|c|}
\hline & $\begin{array}{l}a_{\mathrm{S}} \\
\left(\mathrm{m}^{2} \mathrm{~g}^{-1}\right)\end{array}$ & $V_{\text {micropore }}$ & $V_{\text {mesopore }}$ & $V_{\text {total }}$ & $\begin{array}{l}\mathrm{N} w \mathrm{w} \% \\
\text { (EA) }\end{array}$ & $\begin{array}{l}\text { O at\% } \\
\text { (XPS) }\end{array}$ & $\begin{array}{l}\mathrm{N} \text { at\% } \\
\text { (XPS) }\end{array}$ & $\begin{array}{l}N_{p y} \\
(\%)\end{array}$ & $\begin{array}{l}\mathrm{N}_{\mathrm{gr}} \\
(\%)\end{array}$ & $\begin{array}{l}\mathrm{N}_{\mathrm{ox}} \\
(\%)\end{array}$ & $\begin{array}{l}\mathrm{MgO}(220) \\
\text { FWHM }\left(^{\circ}\right)\end{array}$ & $\begin{array}{l}\text { MgO XRD } \\
\text { 'size' (nm) }\end{array}$ & $\begin{array}{l}\text { Raman } \\
I_{\mathrm{D}} / I_{\mathrm{G}}\end{array}$ & $\begin{array}{l}L_{\mathrm{a}} \\
(\mathrm{nm})\end{array}$ & $\begin{array}{l}E_{1 / 2} \\
\text { (V vs. RHE) }\end{array}$ & $n$ \\
\hline C600 & 409 & $0.15 ; 35 \%$ & $0.28 ; 65 \%$ & 0.42 & 4.89 & 3.07 & 6.36 & 28 & 45 & 27 & 1.51 & 6.46 & 1.37 & 13.8 & 0.69 & 2.19 \\
\hline C800 & 1286 & $0.45 ; 24 \%$ & $1.41 ; 76 \%$ & 1.86 & 5.69 & 2.42 & 6.16 & 34 & 51 & 15 & 1.22 & 7.94 & 1.17 & 16.2 & 0.75 & 3.06 \\
\hline C900 & 1831 & $0.61 ; 20 \%$ & $2.49 ; 80 \%$ & 3.10 & 4.61 & 2.72 & 5.86 & 36 & 51 & 14 & 1.10 & 8.81 & 1.09 & 17.4 & 0.77 & 3.64 \\
\hline C1000 & 1519 & $0.55 ; 20 \%$ & $2.24 ; 80 \%$ & 2.79 & 4.03 & 2.01 & 4.09 & 31 & 46 & 22 & 0.97 & 9.99 & 1.18 & 16.2 & 0.81 & 3.79 \\
\hline
\end{tabular}

${ }^{a} a_{\mathrm{S}}$ is specific surface area, determined by $\mathrm{N}_{2}$ adsorption at $77 \mathrm{~K}$ with BET2 fitting. $V=$ volume in $\mathrm{cm}^{3} \mathrm{~g}^{-1}$. EA $=$ elemental analysis, XPS $=\mathrm{X}$-ray photoelectron spectroscopy. $L_{\mathrm{a}}$ is the in-plane graphite crystalline length calculated from the $I_{\mathrm{D}} / I_{\mathrm{G}}$ ratios. $n$ is the electron transfer number, in mol $\mathrm{e}^{-}$per $\mathrm{mol} \mathrm{O}_{2}$. 
increase may reflect pore growth or convergence near the mesopore/macropore boundary.

We then studied the mesopore and macropore size distribution of carbons C600-C1000 by mercury intrusion (Fig. 2e). This method gives more reliable data on this type of porosity compared with simulation-based methods involving $\mathrm{N}_{2}$ adsorption-desorption isotherms., ${ }^{3,72}$ The measurement is robust and direct, and can also distinguish between pores inside particles and inter-particle volumes in particle agglomerates. At low pyrolysis temperatures (C600, C700), almost no intrusion occurs, reflecting the absence of intraparticulate pores (mesopores or small macropores). When heated to $800{ }^{\circ} \mathrm{C}$, significant mesoporosity develops (C800), creating 5-20 nm pores. As the pyrolysis temperature is increased further, this peak broadens and shifts to larger pore sizes, all the way up to $150 \mathrm{~nm}$. In this temperature range, the pore volume increases dramatically (by nearly $70 \%$ ). Thus, the $700-800{ }^{\circ} \mathrm{C}$ temperature range spans the micropore/mesopore transition, while the 800$900{ }^{\circ} \mathrm{C}$ range spans the mesopore/macropore transition.

The evolution of the mesoporosity and macroporosity can be explained by the growth of $\mathrm{MgO}$ particles, which act as templates. Initially $\left(\leq 700{ }^{\circ} \mathrm{C}\right)$, the $\mathrm{MgO}$ nanoparticles are too small and/or too few to give rise to significant volumes of mesopores. As they grow (C800), they become large enough to serve as templates in the small mesopore region $(\sim 5-20 \mathrm{~nm})$. The further broadening of pores, observed in C900, may result from particle growth and/or agglomeration; the two are hard to distinguish by $\mathrm{N}_{2}$ adsorption alone. The consequent decrease in pore volume in C1000 may arise from further particle agglomeration, leading to segregation of the $\mathrm{MgO}$ from the carbon. Moreover, pore collapse becomes more significant at higher temperatures., ${ }^{3,70,71,73}$

To understand the evolution of the $\mathrm{MgO}$ nanoparticle templates, we studied the XRD patterns of the MgO@carbon composites immediately after pyrolysis (before washing out the $\mathrm{MgO}$ particles). The diffractograms in Fig. 3 shows the typical broad carbon peak at $\sim 24^{\circ}$, corresponding to the (100) planes in carbon, and also three sharp peaks at $36.7^{\circ}, 42.8^{\circ}$ and $62.1^{\circ}$. These peaks are assigned to the (111), (200) and (220) planes of $\mathrm{MgO}$, respectively (JCPDS card 45-0946). Control experiments showed that the $\mathrm{MgO}$ peaks in the $\mathrm{MgO}$ @carbon composites are broader than those in bulk $\mathrm{MgO}$. This broadening proves that the $\mathrm{MgO}$ particles are indeed nanometric and allows following their growth on a semi-quantitative level. As the temperature is increased, the peaks' full widths at half maximum (FWHMs) are narrowed. For $\mathrm{MgO}(220)$, they decrease from 1.5 to 1.0, while the corresponding FWHM in bulk $\mathrm{MgO}(220)$ is just 0.2. The Scherrer equation allows us to compare the approximate sizes of the coherently scattering MgO domains, yielding values between 6.5 and $10 \mathrm{~nm}$ (Table 1). Thus, the drastic mesopore broadening between 800 and $900{ }^{\circ} \mathrm{C}$ cannot arise from the rapid growth of $\mathrm{MgO}$ nanoparticles, since their sizes increase only by several nanometers. Rather, the mesopore broadening and the disappearance of small mesopores, arise from $\mathrm{MgO}$ agglomeration at higher temperatures. Agglomeration decreases the number of $\mathrm{MgO}$ nanoparticles available for templating small mesopores, and the resultant agglomerates serve as templates for large mesopores and macropores.
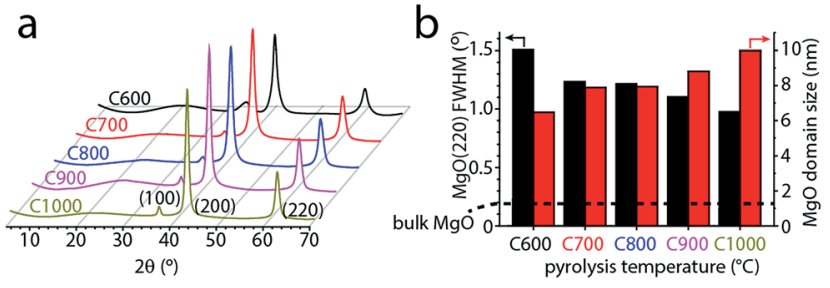

Fig. 3 (a) X-ray diffractograms of the MgOaN:C powders after different pyrolysis temperatures. (b) Full widths at half-maximum (FWHMs) the MgO (220) plane (black) and approximate diameters of coherently scattering domains (red), calculated from the FWHMs using the Scherrer equation. The dashed line marks the bulk MgO (220) FWHM.

In addition to porosity, other structural parameters affect the electrocatalytic behavior of a carbon material. These include conductivity and dopant concentration. The electronic conductivity is linked with the degree of graphitization and the percolation of graphitic domains in the carbon.

Raman spectroscopy affords more quantitative measures of the former, describing the degree of disorder and graphitization in the material by various descriptors. To study the degree of disorder in carbons C600-C1000, we measured their first-order Raman spectra (Fig. 4 and S3†). Two maxima occur near 1345 and $1595 \mathrm{~cm}^{-1}$ for all samples. These were assigned to the D and $\mathrm{G}$ bands of graphite, respectively. The $\mathrm{G}$ band appears in all $\mathrm{sp}^{2}$ carbon Raman spectra, arising from $\mathrm{E}_{2 \mathrm{~g}}$ in-plane bondstretching motions of pairs of $\mathrm{sp}^{2}$ carbons. The $\mathrm{D}$ band is a breathing mode of $\mathrm{sp}^{2}$ carbons in rings; this $\mathrm{A}_{1 \mathrm{~g}}$ vibration is forbidden in perfect graphite yet is activated by symmetry reduction near defects, crystal edges, or impurities. Thus, the $\mathrm{D}$ band is often used as an indicator of disorder. ${ }^{63-66,74}$ Fitting the spectra with just two Lorentzian functions proved impossible, revealing another peak between the two major bands, as well as a shoulder in the low wavenumber side of $\mathrm{D}$ band. The former is assigned to the $\mathrm{D}^{\prime \prime}$ band, typically associated with turbostratic defects (graphene layers slipping out of alignment). ${ }^{63-65}$ The latter shoulder is assigned to the I band, ${ }^{63-65}$ arising from impurity-induced disorder; it has been observed only in disordered carbons. ${ }^{62-64}$
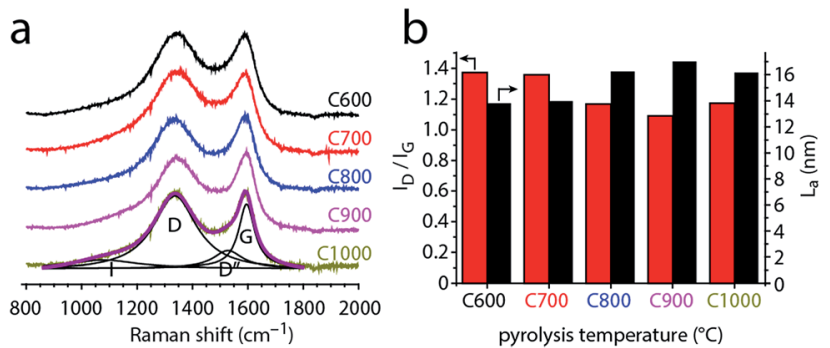

Fig. 4 (a) First-order Raman spectra of carbons C600-C1000, normalized by the $\mathrm{G}$ band intensity. The spectrum of $\mathrm{C} 1000$ is fitted with the I, D, D" and G bands (see text for details). (b) Intensity ratio of the fitted $D$ and $G$ bands (red, left axis), and the in-plane graphite crystalline length $\left(L_{a}\right)$ calculated from the $I_{D} / I_{G}$ ratios. 
The mixed graphitic/disordered nature of the carbons is thus revealed by the presence of the $\mathrm{D}, \mathrm{D}^{\prime \prime}$ and I Raman bands, as well as the relatively high $I_{\mathrm{D}} / I_{\mathrm{G}}$ ratios (1.1-1.4, Fig. 4b). This mixed nature is typical for many $\mathrm{N}$-doped carbons, ${ }^{15,16,64-66}$ in which the nitrogen doping induces structural defects and contributes to local symmetry breaking.

To study how the disorder in the carbon changes with pyrolysis temperature, we followed the $I_{\mathrm{D}} / I_{\mathrm{G}}$ ratio. Fig. $4 \mathrm{~b}$ shows that this ratio generally decreases with pyrolysis temperature. Thus, the carbons become more ordered when heated above $600{ }^{\circ} \mathrm{C}$. This change reflects the in-plane growth of graphitic crystallites, whose lengths $\left(L_{\mathrm{a}}\right)$ can be calculated from the $I_{\mathrm{D}} / I_{\mathrm{G}}$ ratios. The crystallite lengths range from $13.8 \mathrm{~nm}$ for $\mathrm{C} 600 \mathrm{up}$ to $17.4 \mathrm{~nm}$ for C900 (Fig. 4c). The slight decrease in $L_{\mathrm{a}}$ between C900 and C1000 (16.2 $\mathrm{nm}$ ) may reflect shrinking and curving of the graphene layers. ${ }^{75}$ Such shrinking was suggested also by the $\mathrm{N}_{2}$ adsorption porosimetry (Fig. 2c). Interestingly, the $I_{\mathrm{D}} / I_{\mathrm{G}}$ ratio drops sharply from 1.36-1.37 (C600, C700) to 1.09-1.18 (C800, C900, C1000). This step is not correlated with nitrogen loss, which would have explained an increase in order. ${ }^{\mathbf{6 4 - 6 6}}$ Rather, the increasing order shows that the $700-800{ }^{\circ} \mathrm{C}$ temperature range is critical for graphitization catalysis using this particular carbon feedstock (graphitization occurs at different temperatures with different carbon feedstocks, even when using similar MgO catalysts $^{76-78}$ ).

Finally, the concentration and distribution of nitrogen dopants in the carbon matrix plays an important role in its electrocatalytic activity. The bulk concentration of nitrogen was determined by elemental analysis to be $4.0-5.7 \mathrm{wt} \%$ (Table 1). All carbons contained $0.21-0.35 \mathrm{wt} \%$ of residual magnesium, and 1.60-1.85 wt\% of hydrogen (Table S1 $\dagger$ ). We then used XPS to further study the surface and near-surface composition of the carbons, as most relevant for catalysis (Table 1 and Fig. 5). All the carbons contain some surface oxygen (typically 2-3 at\%), with the O 1 s peak constant at $532.1 \pm 0.1 \mathrm{eV}$ (see Fig. S4, ESI $\dagger$ ). The nitrogen concentration is close to 6 at $\%$ and relatively constant between 600 and $800{ }^{\circ} \mathrm{C}$. At higher temperatures it decreases gradually, dropping to 4 at $\%$ at $1000{ }^{\circ} \mathrm{C}$ (Fig. 5b). This decrease corresponds to temperature-driven denitrogenation. ${ }^{79,80}$ Nonetheless, the $\mathrm{N}$ content values are high for single-precursor carbons, without resorting to external nitrogen sources. Fig. 5b also shows the distribution of nitrogen functionalities, which is important to oxygen reduction activity. ${ }^{14-16,18,24}$ Most of the nitrogen is in graphitic form, with pyridinic nitrogens coming close behind. There is an ongoing debate in the literature as to their relative merits in ORR, ${ }^{\mathbf{1 4 - 1 6 , 1 8 , 2 4}}$ so an abundance of both is expected to be beneficial for catalysis. Interestingly, the graphiticto-pyridinic nitrogen ratio remains almost constant at $1.5 \pm 0.1$ throughout the temperature range, even decreasing slightly at higher temperatures. This supports our hypothesis that the micropores form via the interstice cleaning route. Were the micropores formed by etching, pyridinic nitrogens would have been etched away faster than graphitic ones. ${ }^{30}$

We also used high resolution transmission electron microscopy to obtain a qualitative picture of the material (Fig. 6). Pyrolysis at $900{ }^{\circ} \mathrm{C}$, shows a composite of $\mathrm{MgO}$ nanoparticles in a carbon matrix (Fig. 6a-c). The particles themselves are either dispersed or agglomerated, and range between 5 and $10 \mathrm{~nm}$ in size. The final carbons show overlapping mesopores and macropores lined with graphitic shells (Fig. 6d-f). Moreover, a wormlike structure is seen in the high resolution micrographs (Fig. 6f). The black holes are about 3-6 $\AA$ in size, and are typically assigned to micropores. ${ }^{81}$ Scanning electron microscopy (SEM) studies of the carbon series shows that the macroscopic carbon particles become more fractured at higher pyrolysis temperatures (Fig. S5 $\dagger$ ). Mapping the elemental distribution in a small region using energy dispersive X-ray spectroscopy (EDS) reveals a homogeneous distribution of carbon and nitrogen (Fig. S5 $\dagger$ ). While these results (as in many SEM and TEM studies) are qualitative in nature, they complement the surface area, diffraction and spectroscopy measurements, confirming the hierarchical porosity and graphitic network in the carbon.

\subsection{Oxygen reduction electrocatalysis}

To study how the evolving microstructure and composition affect electrocatalytic activity, we tested the carbons as ORR electrocatalysts under basic conditions. Cyclic voltammetry (CV, Fig. 7a) in an $\mathrm{O}_{2}$-saturated solution reveals that the activity improves with higher pyrolysis temperature (the onset and halfwave potentials for ORR shift positively). This finding is supported by potentiostatic EIS. The semicircle widths in the EIS-derived Nyquist plot (Fig. 7b) correspond to the chargetransfer resistance, and thus represent kinetic barriers during electrocatalysis. ${ }^{21,82}$ These values decrease steadily as pyrolysis temperature is raised. Both the $\mathrm{CV}$ and EIS data reveal a significant jump in activity between $600{ }^{\circ} \mathrm{C}$ and $700{ }^{\circ} \mathrm{C}$, and
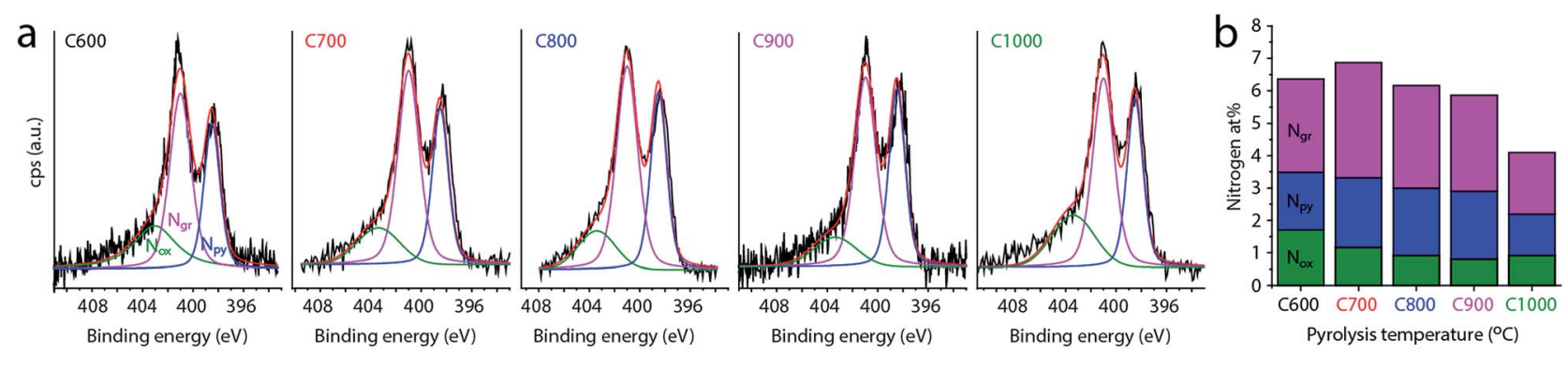

Fig. 5 (a) X-ray photoelectron spectra of carbons $\mathrm{C} 600-\mathrm{C} 1000$ in the $\mathrm{N} 1 \mathrm{~s}$ region, with best fits of three nitrogen functionalities: pyrinidic ( $\mathrm{N}_{\mathrm{py}}$ $398.5 \mathrm{eV})$, graphitic $\left(\mathrm{N}_{\mathrm{gr}}, 401.1 \mathrm{eV}\right.$ ) and 'oxidized' ( $\left.\mathrm{N}_{\mathrm{ox}}, 403.4 \mathrm{eV}\right)$. (b) Distribution of nitrogen functionalities in each carbon sample. 


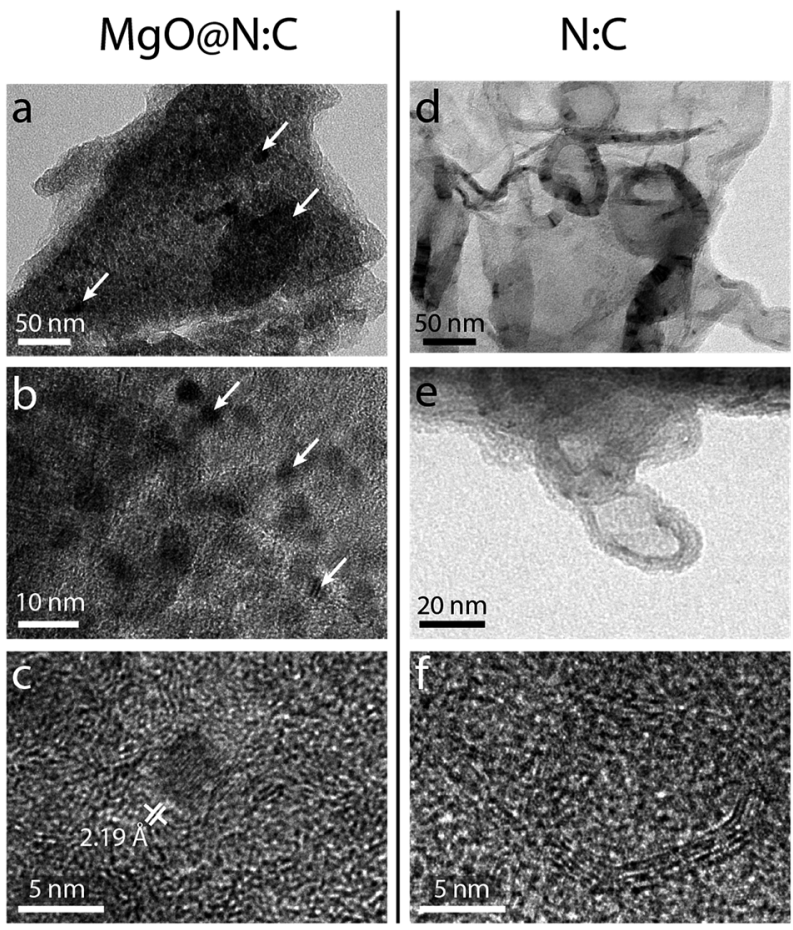

Fig. 6 High resolution transmission electron micrographs of C900, $(a-c)$ before acid washing, and $(d-f)$ after washing out the $\mathrm{MgO}$ with acid and annealing. Arrows mark $\mathrm{MgO}$ (a) agglomerates and (b) discrete nanoparticles.

a further monotonous increase in activity as pyrolysis temperature is increased.

This trend was quantified by voltammetry on a rotating disk; the Koutecký-Levich equation allows one to separate the masstransfer component of the current (arising from controlled convection) from the kinetic (catalytic) current component. This yields the number of electrons transferred in the reaction per $\mathrm{O}_{2}$ molecules consumed (Fig. $7 \mathrm{c}$ and $\mathrm{S6} \dagger$ ). The closer this value is to 2, the more $\mathrm{H}_{2} \mathrm{O}_{2}$ is produced and released without being reduced to $\mathrm{OH}^{-}$nor decomposed. This is useful when $\mathrm{H}_{2} \mathrm{O}_{2}$ production is pursued, ${ }^{83}$ and unwanted when complete $\left(4 \mathrm{e}^{-}\right)$ ORR is desired, e.g. in fuel cell or battery cathodes. ${ }^{14-16,18,24}$
As Fig. 7c reveals, C600 catalyzes only the $2 \mathrm{e}^{-}$reduction. Thus, despite containing over 6 at\% nitrogen, its electrocatalytic activity is similar to that of an undoped carbon derived from magnesium citrate (the latter is similar enough to magnesium nitrilotriacetate so that one would expect the formation of similar carbon microstructures ${ }^{15,23}$ ). This shows that a high nitrogen content is by itself insufficient for ORR activity. Rather, the nitrogen sites must also be sufficiently exposed, which requires a high surface area.

Conversely, carbons pyrolyzed at $700-800{ }^{\circ} \mathrm{C}$ perform the $2 \mathrm{e}^{-}$ and $4 \mathrm{e}^{-}$reductions equally well, with an effective $n=3.04-3.06$. Finally, the high temperature carbons C900 and C1000 show good performance towards full $4 \mathrm{e}^{-}$ORR, with $n=3.64-3.79$.

Deriving reliable structure-activity links is a challenge in the field of materials science in general, and electrocatalysis in particular. This is especially true in the case of $\mathrm{N}$-doped carbons, because raising the pyrolysis temperature changes several properties of the material simultaneously: porosity, surface area, graphitization, nitrogen concentration and distribution. Nonetheless, we can identify some structureactivity trends:

(1) The ORR activity improves with the graphitization temperature, in line with the observations of Liang, ${ }^{26}$ Müllen, ${ }^{84}$ and others. ${ }^{15-17}$ However, this improvement does not follow the concentration of nitrogen, which is depleted at higher pyrolysis temperatures. Thus, microstructural considerations play the deciding role over the entire $600-1000{ }^{\circ} \mathrm{C}$ temperature range.

(2) The dramatic increase in ORR activity at lower temperatures $\left(600-700{ }^{\circ} \mathrm{C}\right)$ correlates with the increase in surface area. Although the chemical nature of active sites is determined by the bulk and surface composition of the doped carbons, ${ }^{25-27}$ the number of exposed active sites is correlated with the surface area. Heating from $600{ }^{\circ} \mathrm{C}$ to $700{ }^{\circ} \mathrm{C}$ increases the surface area, and may expose many active sites, thus boosting electrocatalysis. Even at higher temperatures (up to $900^{\circ} \mathrm{C}$ ), the surface area may be behind the ORR activity rise.

(3) Several studies have shown a positive correlation between ORR activity and density of graphitic crystallite edges. ${ }^{32}$ This correlation was explained either in terms of exposing more (supposedly more active) pyridinic nitrogens, and/or by the
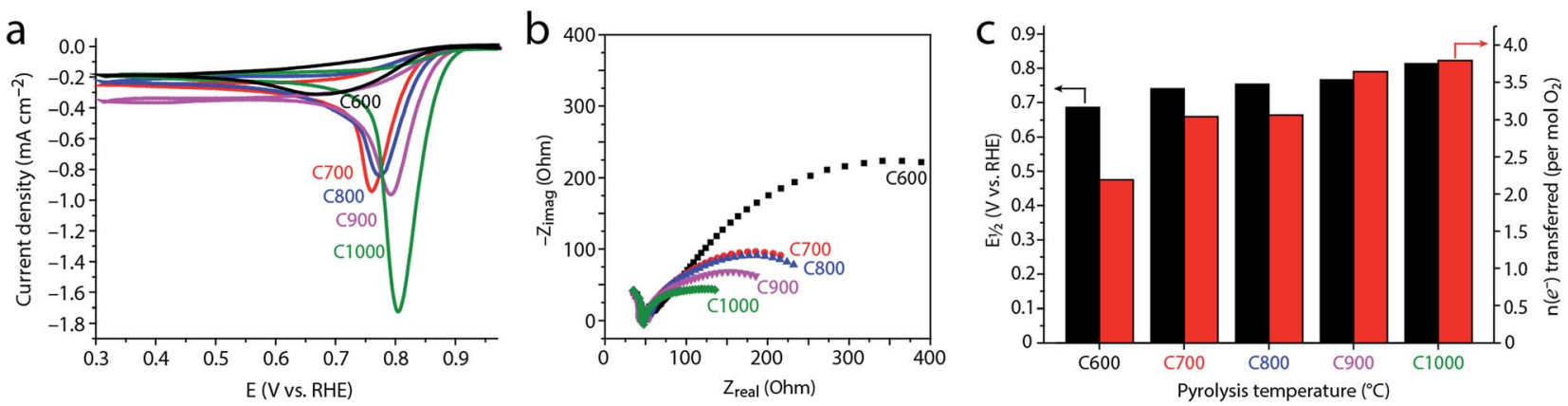

Fig. 7 Electrocatalytic oxygen reduction in $0.1 \mathrm{M} \mathrm{KOH}(\mathrm{pH}=13)$ at $25^{\circ} \mathrm{C}$ on carbons $\mathrm{C} 600-\mathrm{C} 1000$. (a) Cyclic voltammograms (CV) in an $\mathrm{O}_{2}$ saturated solution, scan rate $10 \mathrm{mV} \mathrm{s}^{-1}$, after subtracting the capacitive currents measured in an $\mathrm{O}_{2}$-free $\left(\mathrm{N}_{2}\right.$-saturated) solution. (b) Nyquist plots obtained by potentiostatic electrochemical impedance spectroscopy at $E_{1 / 2}$. (c) Half-wave potentials $\left(E_{1 / 2}\right)$, obtained at a rotating speed of 1600 rpm (black, left axis); number of electrons transferred in the catalytic reactions ( $\mathrm{mol}$ per $\mathrm{mol} \mathrm{O}_{2}$ ), obtained by Koutecký-Levich analysis at different rotation speeds (red, right axis). 


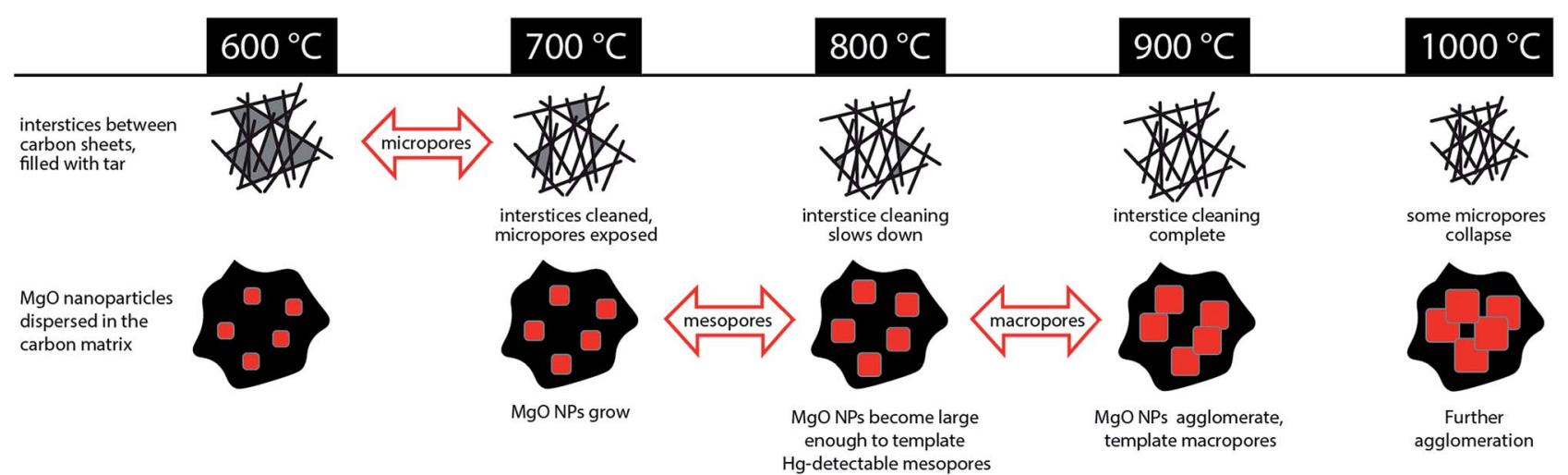

Fig. 8 Evolution of hierarchical porosity from $600^{\circ} \mathrm{C}$ to $1000^{\circ} \mathrm{C}$ in MgNTA-derived carbon. Red arrows mark significant transitions in porosity type.

intrinsic activity of graphene edges. ${ }^{32,85,86}$ In carbons C600C1000 we see the opposite trend: the degree of disorder decreases with pyrolysis temperature, yet electrocatalysis improves. This suggests that the benefits of graphitization (e.g. conductivity) may outweigh the loss of catalytic sites.

(4) The similar ORR activity of C700 and C800 suggests that the mesopore transition $\left(700-800{ }^{\circ} \mathrm{C}\right)$ plays a smaller role in ORR electrocatalysis than the micropore transition (600-700 $\left.{ }^{\circ} \mathrm{C}\right)$. However, it is possible that this "mesopore transition" is arbitrary, as it is defined by the ability of $\mathrm{Hg}$ intrusion to detect smaller pores. In this case, the beneficial effect of mesopores may be gradual, spreading over the entire temperature range.

(5) The second heat-treatment step at $1000{ }^{\circ} \mathrm{C}$ may play a separate role in determining the carbon properties. However, we expect the temperature of the first pyrolysis to determine most carbon properties, ${ }^{26}$ since the $\mathrm{MgO}$ particles are then still present in the particles to act as graphitization catalysts and pore templates. Moreover, as all the carbons were annealed at the same temperature, most of the differences in their properties should arise from the first step.

\section{Conclusions}

The evolution of hierarchical porosity, as well as other microstructural and compositional properties of MgNTA-derived carbons, have been studied in the $600-1000{ }^{\circ} \mathrm{C}$ temperature range by a variety of experimental methods. As summarized in Fig. 8 and Table 1 , the porosity may be divided in two main classes, evolving in parallel. The microporosity, on one hand, is derived mostly from the evacuation of tarry matter from interstices between aromatic sheets. The transition to microporosity occurs between $600{ }^{\circ} \mathrm{C}$ and $700{ }^{\circ} \mathrm{C}$, and is accompanied by an increase in surface area, and a dramatic jump in ORR activity. Mesoporosity and macroporosity, on the other hand, are templated by spontaneously forming $\mathrm{MgO}$ nanoparticles. Discrete $\mathrm{MgO}$ particles give rise to small mesoporosity $\left(>800{ }^{\circ} \mathrm{C}\right)$, whereas $\mathrm{MgO}$ agglomerates act as macropore templates $(>900$ $\left.{ }^{\circ} \mathrm{C}\right)$. At a higher temperature $\left(1000{ }^{\circ} \mathrm{C}\right)$, some pores collapse, decreasing surface area. The degree of order increases with pyrolysis temperature, suggesting an improved conductivity in the higher-temperature carbons. A significant graphitization step occurs between 700 and $800{ }^{\circ} \mathrm{C}$, suggesting enhanced graphitization catalysis by $\mathrm{MgO}$ at this temperature.

Electrocatalytic ORR activity increases with pyrolysis temperature. It is not dictated by nitrogen content nor by edge plane density, both of which decrease along the series. In fact, ORR activity correlates best with microporosity (surface area and micropore volume), emphasizing the importance of active site exposure. Overall, understanding the evolution of microstructure in pyrolytic self-templating carbons can help in developing this important class of materials.

\section{Acknowledgements}

We thank Dr C. S. Sandu, P. Mettraux, Dr S. Mischler, Prof. N. Setter (EPFL) and the CIME-EPFL team for TEM and XPS measurements, and T. K. Slot for help with Raman fitting. This work is part of the Research Priority Area Sustainable Chemistry of the UvA, http://suschem.uva.nl.

\section{Notes and references}

1 W. Wreszinski, Der Papyrus Ebers, ed. J. C. Hinrichs, Leipzig, 1913.

2 C. A. Mitchell and T. C. Hepworth, Inks: their composition and manufacture, Griffin \& Co., London, 1937.

3 R. C. Bansal, J.-B. Donnet and F. Stoeckli, Active Carbon, Marcel Dekker, New York, 1988.

4 M. C. Mittelmeijer-Hazeleger, PhD thesis, University of Amsterdam, 2006.

5 F. Rodríguez-Reinoso, Carbon, 1998, 36, 159-175.

6 E. Lam and J. H. T. Luong, ACS Catal., 2014, 4, 3393-3410.

7 M. Winter and R. J. Brodd, Chem. Rev., 2004, 104, 4245-4270.

8 F. Cheng and J. Chen, Chem. Soc. Rev., 2012, 41, 2172-2192.

9 I. Aldama, V. Barranco, T. A. Centeno, J. Ibañez and J. M. Rojo, J. Electrochem. Soc., 2016, 163, A758-A765.

10 A. G. Pandolfo and A. F. Hollenkamp, J. Power Sources, 2006, 157, 11-27.

11 T. Lin, I.-W. Chen, F. Liu, C. Yang, H. Bi, F. Xu and F. Huang, Science, 2015, 350, 1508-1513. 
12 Q. Wang, J. Yan and Z. Fan, Energy Environ. Sci., 2016, 9, 729762.

13 Y. Deng, Y. Xie, K. Zou and X. Ji, J. Mater. Chem. A, 2016, 4, 1144-1173.

14 Handbook of Fuel Cells, ed. W. Vielstich, A. Lamm and H. A. Gasteiger, John Wiley \& Sons, 2003, vol. 2.

15 N. Daems, X. Sheng, I. F. J. Vankelecom and P. P. Pescarmona, J. Mater. Chem. A, 2014, 2, 4085-4110.

16 L. Dai, Y. Xue, L. Qu, H.-J. Choi and J.-B. Baek, Chem. Rev., 2015, 115, 4823-4892.

17 M. Shao, Q. Chang, J.-P. Dodelet and R. Chenitz, Chem. Rev., 2016, 116, 3594-3657.

18 Z. Yang, H. Nie, X. Chen, X. Chen and S. Huang, J. Power Sources, 2013, 236, 238-249.

19 J. R. Varcoe, P. Atanassov, D. R. Dekel, A. M. Herring, M. A. Hickner, P. A. Kohl, A. R. Kucernak, W. E. Mustain, K. Nijmeijer, K. Scott, T. Xu and L. Zhuang, Energy Environ. Sci., 2014, 7, 3135-3191.

20 Q. He and E. J. Cairns, J. Electrochem. Soc., 2015, 162, F1504F1539.

21 H.-W. Liang, X. Zhuang, S. Brüller, X. Feng and K. Müllen, Nat. Commun., 2014, 5, 4973.

22 Z. Xu, X. Zhuang, C. Yang, J. Cao, Z. Yao, Y. Tang, J. Jiang, D. Wu and X. Feng, Adv. Mater., 2016, 28, 1981-1987.

23 D. Eisenberg, W. Stroek, N. J. Geels, C. S. Sandu, A. Heller, N. Yan and G. Rothenberg, Chem.-Eur. J., 2016, 22, 501-505.

24 D. Guo, R. Shibuya, C. Akiba, S. Saji, T. Kondo and J. Nakamura, Science, 2016, 351, 361-365.

25 K. Wan, Z. Yu, X. Li, M. Liu, G. Yang, J. Piao and Z. Liang, ACS Catal., 2015, 5, 4325-4332.

26 G. Long, K. Wan, M. Liu, X. Li, Z. Liang and J. Piao, Chin. J. Catal., 2015, 36, 1197-1204.

27 K. Wan, G.-F. Long, M.-Y. Liu, L. Du, Z.-X. Liang and P. Tsiakaras, Appl. Catal., B, 2015, 165, 566-571.

28 K. Wan, Z.-P. Yu and Z.-X. Liang, Catalysts, 2015, 5, 10341045.

29 J. Zhang, D. Liu, H. Song, Z. Liang, X. Guo, L. Du and S. Liao, RSC Adv., 2016, 6, 19515-19521.

30 D. Eisenberg, W. Stroek, N. J. Geels, S. Tanase, M. Ferbinteanu, S. J. Teat, P. Mettraux, N. Yan and G. Rothenberg, Phys. Chem. Chem. Phys., 2016, 18, 2077820783.

31 T. K. Slot, D. Eisenberg, D. van Noordenne, P. Jungbacker and G. Rothenberg, Chem.-Eur. J., 2016, 22, 12307-12311.

32 W. He, Y. Wang, C. Jiang and L. Lu, Chem. Soc. Rev., 2016, 45, 2396-2409.

33 C. Li, H. Zhang, D. Jiang and Q. Yang, Chem. Commun., 2007, 547-558.

34 J. Liang, Y. Zheng, J. Chen, J. Liu, D. Hulicova-Jurcakova, M. Jaroniec and S. Z. Qiao, Angew. Chem., Int. Ed., 2012, 51, 3892-3896.

35 S. Israel, I. Gurevitch and M. S. Silverstein, Polymer, 2015, 72, 453-463.

36 N. López-Salas, D. Carriazo, M. C. Gutiérrez, M. L. Ferrer, C. O. Ania, F. Rubio, A. Tamayo, J. L. G. Fierro and F. del Monte, J. Mater. Chem. A, 2016, 4, 9146-9159.
37 W. Schwieger, A. G. Machoke, T. Weissenberger, A. Inayat, T. Selvam, M. Klumpp and A. Inayat, Chem. Soc. Rev., 2016, 45, 3353-3376.

38 R. J. White, in RSC Green Chemistry, ed. R. J. White, Royal Society of Chemistry, Cambridge, 2015, pp. 3-49.

39 M. Inagaki, M. Kato, T. Morishita, K. Morita and K. Mizuuchi, Carbon, 2007, 45, 1121-1124.

40 C. Zhang, M. Antonietti and T.-P. Fellinger, Adv. Funct. Mater., 2014, 24, 7655-7665.

41 S. Gao, X. Wei, H. Fan, L. Li, K. Geng and J. Wang, Nano Energy, 2015, 13, 518-526.

42 M. Wahid, G. Parte, D. Phase and S. Ogale, J. Mater. Chem. A, 2015, 3, 1208-1215.

43 L. Wei, H. E. Karahan, K. Goh, W. Jiang, D. Yu, Ö. Birer, R. Jiang and Y. Chen, J. Mater. Chem. A, 2015, 3, 7210-7214.

44 A. A. Zakhidov, R. H. Baughman, Z. Iqbal, C. Cui, I. Khayrullin, S. O. Dantas, J. Marti and V. G. Ralchenko, Science, 1998, 282, 897-901.

45 R. Ryoo, S. H. Joo and S. Jun, J. Phys. Chem. B, 1999, 103, 7743-7746.

46 H.-W. Liang, W. Wei, Z.-S. Wu, X. Feng and K. Müllen, J. Am. Chem. Soc., 2013, 135, 16002-16005.

47 D.-Y. Kang and J. H. Moon, Sci. Rep., 2014, 4, 5392.

48 Y. Meng, D. Gu, F. Zhang, Y. Shi, H. Yang, Z. Li, C. Yu, B. Tu and D. Zhao, Angew. Chem., 2005, 117, 7215-7221.

49 W. He, C. Jiang, J. Wang and L. Lu, Angew. Chem., Int. Ed., 2014, 53, 9503-9507.

50 H. Tamon, H. Ishizaka, T. Yamamoto and T. Suzuki, Carbon, 1999, 37, 2049-2055.

51 A. Allahbakhsh and A. R. Bahramian, Nanoscale, 2015, 7, 14139-14158.

52 T. Morishita, Y. Soneda, T. Tsumura and M. Inagaki, Carbon, 2006, 44, 2360-2367.

53 T. Morishita, T. Tsumura, M. Toyoda, J. Przepiórski, A. W. Morawski, H. Konno and M. Inagaki, Carbon, 2010, 48, 2690-2707.

54 M. Inagaki, H. Orikasa and T. Morishita, RSC Adv., 2011, 1, 1620-1640.

55 M. Sevilla and A. B. Fuertes, J. Mater. Chem. A, 2013, 1, 13738-13741.

56 B. Xu, H. Duan, M. Chu, G. Cao and Y. Yang, J. Mater. Chem. A, 2013, 1, 4565.

57 X. Y. Chen, Y. Y. He, H. Song and Z. J. Zhang, Carbon, 2014, 72, 410-420.

58 W. Jiang, Z. Luo, X. Jia and X. Wu, J. Solid State Electrochem., 2015, 19, 795-803.

59 G. A. Ferrero, M. Sevilla and A. B. Fuertes, Carbon, 2015, 88, 239-251.

60 P. Scherrer, Nachrichten von der Gesellschaft der Wissenschaften zu Göttingen, 1918, pp. 98-100.

61 P. Scardi, M. Leoni and R. Delhez, J. Appl. Crystallogr., 2004, 381-390.

62 K. Angoni, Carbon, 1993, 31, 537-547.

63 A. Cuesta, P. Dhamelincourt, J. Laureyns, A. Martínez-Alonso and J. M. D. Tascón, Carbon, 1994, 32, 1523-1532.

64 S. Maldonado, S. Morin and K. J. Stevenson, Carbon, 2006, 44, 1429-1437. 
65 S. Zhang, Z. Li, K. Ueno, R. Tatara, K. Dokko and M. Watanabe, J. Mater. Chem. A, 2015, 3, 17849-17857.

66 L. G. Bulusheva, A. V. Okotrub, I. A. Kinloch, I. P. Asanov, A. G. Kurenya, A. G. Kudashov, X. Chen and H. Song, Phys. Status Solidi B, 2008, 245, 1971-1974.

67 L. G. Cançado, K. Takai, T. Enoki, M. Endo, Y. A. Kim, H. Mizusaki, A. Jorio, L. N. Coelho, R. Magalhães-Paniago and M. A. Pimenta, Appl. Phys. Lett., 2006, 88, 163106.

68 J. S. Budkuley and G. K. Naik, Thermochim. Acta, 1998, 320, 115-120.

69 M. Thommes, K. Kaneko, A. V. Neimark, J. P. Olivier, F. Rodriguez-Reinoso, J. Rouquerol and K. S. W. Sing, Pure Appl. Chem., 2015, 87, 1051-1069.

70 R. H. Hurt, D. R. Dudek, J. P. Longwell and A. F. Sarofim, Carbon, 1988, 26, 433-449.

71 C. L. Burket, R. Rajagopalan, A. P. Marencic, K. Dronvajjala and H. C. Foley, Carbon, 2006, 44, 2957-2963.

72 F. Rouquerol, J. Rouquerol and K. Sing, Adsorption by powders \& porous solids: principles, methodology and applications, 1st edn, 1999.

73 T. Kyotani, Carbon, 2000, 38, 269-286.

74 B. Hua, N. Yan, M. Li, Y.-F. Sun, J. Chen, Y.-Q. Zhang, J. Li, T. Etsell, P. Sarkar and J.-L. Luo, J. Mater. Chem. A, 2016, 4, 9080-9087.

75 Y. Li, Y.-S. Hu, H. Li, L. Chen and X. Huang, J. Mater. Chem. A, 2015, 4, 96-104.

76 M. H. Rümmeli, F. Schäffel, T. de los Arcos, D. Haberer, A. Bachmatiuk, C. Kramberger, P. Ayala, E. Borowiak-
Palen, D. Adebimpe, T. Gemming, A. Leonhardt, B. Rellinghaus, L. Schultz, T. Pichler and B. Büchner, Phys. Status Solidi B, 2008, 245, 1939-1942.

77 M. H. Rümmeli, A. Bachmatiuk, A. Scott, F. Börrnert, J. H. Warner, V. Hoffman, J.-H. Lin, G. Cuniberti and B. Büchner, ACS Nano, 2010, 4, 4206-4210.

78 A. Bachmatiuk, R. G. Mendes, C. Hirsch, C. Jähne, M. R. Lohe, J. Grothe, S. Kaskel, L. Fu, R. Klingeler, J. Eckert, P. Wick and M. H. Rümmeli, ACS Nano, 2013, 7, 10552-10562.

79 A. Aijaz, N. Fujiwara and Q. Xu, J. Am. Chem. Soc., 2014, 136, 6790-6793.

80 G. Panomsuwan, N. Saito and T. Ishizaki, Phys. Chem. Chem. Phys., 2015, 17, 6227-6232.

81 T. Miyazaki, T. Oshida, T. Nakatsuka, H. Yamamoto, M. Okamoto and M. Endo, Mol. Cryst. Liq. Cryst., 2002, 388, 85-90.

82 P. Kichambare, J. Kumar, S. Rodrigues and B. Kumar, J. Power Sources, 2011, 196, 3310-3316.

83 Y. Liu, X. Quan, X. Fan, H. Wang and S. Chen, Angew. Chem., Int. Ed., 2015, 54, 6837-6841.

84 R. Liu, D. Wu, X. Feng and K. Müllen, Angew. Chem., Int. Ed., 2010, 49, 2565-2569.

85 P. Matter, L. Zhang and U. Ozkan, J. Catal., 2006, 239, 83-96.

86 R. Silva, J. Al-Sharab and T. Asefa, Angew. Chem., Int. Ed., 2012, 51, 7171-7175. 